\title{
Norma e variação: valores simbólicos em oposição ${ }^{1}$
}

\author{
Roberto Gomes Camacho \\ Universidade Estadual Paulista "Júlio de Mesquita Filho" (UNESP), \\ São José do Rio Preto, São Paulo, Brasil \\ camacho@sjrp.unesp.br
}

DOI: http://dx.doi.org/10.21165/el.v46i1.1735

\begin{abstract}
Resumo
Eckert (2000) inaugurou uma nova tendência na Sociolinguística ao propor um conceito renovado de regra variável, que passou a constituir o espaço privilegiado da construção do significado social. No âmbito desse quadro teórico, estabeleceu-se como objetivo para este trabalho a análise das dinâmicas e das práticas sociais de dois grupos de estudantes, ideologicamente opostos para examinar como o processo variável de concordância nominal, como a regra variável de pluralidade no SN, praticada na comunidade como um todo, pode ser aproveitada como indexador da construção de identidade por membros de diferentes comunidades de prática e, por outro, para discutir como casos de variação como esse, convivendo no próprio ambiente escolar com a própria questão normativa, estão conectados com a situação de ensino.
\end{abstract}

Palavras-chave: variação estilística; identidade; campo indexical.

\section{Norm and variation: symbolic values in opposition}

\begin{abstract}
Eckert (2000) brought a new trend in Sociolinguistics when she proposed a new concept of variable rule, which now constitutes a privileged space of the construction of social meaning. Within this theoretical framework, the purpose of this paper was to analyze the dynamics and social practices of two groups of students ideologically opposed to examine, on one hand, how the variable process of nominal agreement, such as the variable rule of NP plurality, practiced in the community as a whole, can be exploited as an index of the identity construction by members of different communities of practice and, on the other hand, to discuss how cases of variation like that, living together with matters of normative rules in the school environment itself, are connected with the teaching situation.
\end{abstract}

Keywords: stylistic variation; identity; indexical field.

\section{Introdução}

A aquisição de uma variedade de prestígio é vista por Labov (1972) como um processo de conformidade gradual da linguagem do indivíduo, da infância ao fim da adolescência, com a variedade de prestígio praticada por falantes adultos do mesmo grupo social.

Um dos obstáculos cruciais à finalização do processo é o conflito entre diferentes sistemas de valores, um tipo de obstáculo que nem sempre se deseja transpor, já que o domínio completo da variedade padrão pode estar em tensão constante com outro valor simbólico, o de resistência cultural.

\footnotetext{
${ }^{1}$ Palestra proferida com o mesmo título na mesa-redonda Norma, variação e ensino, no $64^{\circ}$ Seminário do Grupo de Estudos Linguísticos do Estado de São Paulo (GEL), realizado na Faculdade de Ciências e Letras, UNESP, câmpus de Assis, de 5 a 8 de julho de 2016.
} 
Chambers (1995) entende que, se há pressões sociais que favorecem de fato a promoção de uma variedade padrão, deve haver também pressões contrárias que favoreçam a variedade de fala mais informal sem muito apego a regras normativas. Essas pressões contrárias são tácitas e não conscientes por não serem facilmente identificáveis, ao contrário das forças que favorecem a variedade padrão, que são, por exemplo, claramente identificáveis na defesa de pais de classe média do que entendem ser a "boa" linguagem para seus filhos aprenderem, da correção que os professores fazem no uso de seus alunos em sala de aula, nas cartas enviadas à redação de jornais e revistas deplorando deslizes dos usos prescritos etc.

Em contraste, sustenta Chambers (1995), as pressões sociais que mantêm as formas não padrão não dispõem de lobistas assim tão identificáveis. Ninguém reclama publicamente de formas hipercorretas na mídia, ou da uniformidade de sotaques entre locutores de telejornais, ou mesmo da tirania das convenções ortográficas.

Só para dar um exemplo recente de uso de formas hipercorretas, um blogueiro conhecido da Veja Online rasgou-se em elogios ao discurso de posse de Temer dizendo: "Pela primeira vez em muito tempo, sentia-se a presença de uma autoridade que inspirava respeito. Sem gritos, sem atropelos à língua, sem suor, sem dedo em riste. Temer, com um risinho contido, recorreu até a uma mesóclise"2.

Ao questionar por que as pessoas nem sempre se exprimem como obviamente acreditam que deveriam exprimir-se, Labov (1972) responde postulando a existência de um conjunto oposto de normas encobertas, que atribui valores positivos à variedade mais informal e não necessariamente à variedade padrão. Segundo Chambers (1995, p. 222223), esse valor tácito ficou conhecido como "prestígio encoberto" (covert prestige), o termo que Trudgill (1972) lhe atribuiu ao fornecer também a primeira evidência objetiva para o fenômeno com base em diferenças de comportamento de gênero.

Observou esse autor que, na fala de Norwich, $50 \%$ dos homens que assumem falar a variedade não padrão, usam, na realidade, a variedade padrão com maior frequência; na direção contrária, $68 \%$ das mulheres que assumem usar a variedade padrão, empregam, na realidade, formas da variedade não padrão. Esses resultados não apenas fornecem evidência de que os homens atribuem um prestígio encoberto à forma não padrão, mas também comprovam que a variedade linguística que se emprega é fator concorrente para a construção de identidade social.

Basta ver o que diz Eckert (2005), ao repropor o conceito de variável linguística como o lugar da construção do significado social da linguagem, desenvolvido, segundo a autora, no próprio processo de articulação e de envolvimento dos indivíduos com as comunidades de práticas em que participam.

Assim, se a variedade é considerada socialmente estigmatizada, em contraposição à norma padrão, veiculada principalmente pelo sistema de ensino, instaura-se um conflito entre os valores que a instituição escolar pretende inculcar e os que o aprendiz compartilha com sua própria comunidade de prática (ECKERT, 2005) e que, em última instância, identificam-no simbolicamente como membro dela. Se esse conflito já é um grave problema para o ensino, mais grave ainda são os casos de variação estilística, que pretendo discutir neste trabalho.

\footnotetext{
2 Disponível em: <http://veja.abril.com.br/blog/reinaldo/geral/um-discurso-impecavel-na-forma-e-no-
} conteudo $>$. Acesso em: 1 jun. 2016. 
A tradição recente da sociolinguística variacionista define estilo como o uso de diferentes formas no mesmo contexto e com o mesmo valor de verdade; a visão de estilo defendida por Eckert (2008), no entanto, exclui essa separação assim tão nítida entre forma e conteúdo sob a condição de que o social é eminentemente uma construção erguida sobre os alicerces do próprio conteúdo de vida das pessoas. Diferentes formas de dizer coisas ou significados potenciais para enunciar têm o objetivo de sinalizar diferentes modos de ser.

O estilo da persona (e são várias as máscaras sociais que se assumem) é o melhor nível para abordar o significado da variação, pois é nele que se conectam estilos propriamente linguísticos com outros sistemas estilísticos, como uso do vestuário, de adereços etc., relacionados com a formação ideológica que os falantes compartilham e que, por isso mesmo, povoa o imaginário social.

A prática estilística se identifica, assim, com um processo de bricolagem (HEBDIGE, 1984 apud ECKERT, 2008), já que os recursos linguísticos podem ser interpretados e combinados com outros mecanismos para construir uma entidade significativa mais complexa. Estilo e identidade são, sob esse prisma, conceitos fortemente associados: os falantes atribuem um novo significado social à variação, aproveitando-se da já existente no mercado linguístico, situação que implica certo grau de agentividade.

Dito isso, neste texto, pretendo examinar o modo como processos variáveis de marcação de plural no SN, investidos de significação estilística, são usados por membros de duas comunidades de prática como indexadores de construção da identidade. Pretendo mostrar, por um lado, como a regra variável de pluralidade no SN, praticada na comunidade como um todo, pode ser "aproveitada", digamos assim, como indexador da construção de identidade de diferentes comunidades de prática e, por outro, como casos mais fluidos de variação como esse, convivendo no próprio ambiente escolar, estão conectados com a situação de ensino.

O plano desta exposição é analisar, em primeiro lugar, as dinâmicas e as práticas sociais de dois grupos de estudantes opostos, de uma mesma escola pública da cidade de São José do Rio Preto, definidos por seus próprios membros, como funkeiros e ecléticos, em trabalho de doutorado desenvolvido por Salomão-Conchalo (2015) sob minha orientação. Em segundo lugar, revisar alguns conceitos de prestígio e estigmatização em relação ao de norma para discutir que atenção o ensino de língua materna deve devotar a casos de comunidades de prática como os que são aqui examinados.

A análise, que se pretende fazer na primeira parte, debruça-se sobre o comportamento de grupos de jovens que estão em pleno processo de desenvolvimento de suas identidades individuais e grupais, e isso no contexto escolar, que é, por definição, um ambiente propício à manifestação de rebeldia, especialmente porque o ambiente escolar representa, em certas circunstâncias, um espaço de repressão da identidade, na medida em que o corpo institucional de uma escola, constituído por professores, coordenadores e administradores, normalmente não reconhece a diversidade social e linguística do corpo discente nem mesmo no processo de ensino-aprendizagem. 


\section{A prática estilística como indexador da construção de identidade}

A escolha de duas CPs entre outras existentes se assentou no fato de serem ideologicamente opostas no espaço social da escola. Embora a CP dos funkeiros seja constituída por 15 indivíduos, distribuídos pelos dois períodos escolares, os alunos do período matutino, mais maduros, já dispõem de uma concepção mais nítida de sua própria identidade social e, por conseguinte, de afiliação grupal. Para os efeitos desta exposição, os funkeiros, tomados como $\mathrm{CP}$, são constituídos por quatro indivíduos, três meninos e uma menina.

Dois membros dessa CP, assim delimitada, desempenham forte papel de liderança, passível de se observar no grau considerável de influência que exercem sobre os outros membros. A menina selecionada lidera as demais, enquanto o jovem coordena as ações dos meninos. Essa jovem, no entanto, também se rende à influência das ações do líder do gênero oposto, como se pode verificar em algumas situações em que ela acompanha, sem questionamento, o comportamento do líder.

De uma forma geral, o grupo dos funkeiros pode ser considerado uma rede social densa e múltipla (MILROY, 1987), pois todos os membros se conhecem bem e se conectam por mais de um tipo de relação (estudam juntos, são amigos e são ou já foram vizinhos). No entanto, uma verificação das relações intragrupais permite notar que o líder e a jovem que constituem membros centrais estão mais fechados em suas práticas sociais que os membros mais periféricos.

O grupo dos ecléticos, formado por cerca de dez jovens, é também representado, para os efeitos desta pesquisa, por três meninos e uma menina. Essa CP tem um funcionamento diferente do grupo anterior, derivado, certamente, do modo como os membros da CP se subdividem, ou seja, não há membros exclusivamente líderes e centrais ou exclusivamente periféricos. Cada membro muda de posição na hierarquia, que, em consequência, é também mutável na dependência dos interesses e das práticas sociais em pauta. Desse modo, todos podem ser líderes, membros centrais ou indivíduos à margem da CP dependendo da natureza da atividade envolvida. A falta de um líder dentro do grupo acaba por propiciar um grau mais elevado de dialogismo entre os membros e participação coletiva nas decisões a tomar sobre as ações e práticas sociais futuras.

Como já mencionado, o trabalho etnográfico, postulado pelos integrantes da "terceira onda" (ECKERT, 2012), é em geral qualitativo, mas não despreza o estudo quantitativo de base variacionista, uma vez que os dois procedimentos não são contraditórios, mas complementares. A hipótese sustentada é que deve haver uma correlação entre centralidade e perifericidade grupal e expressão linguística de pluralidade no SN. Nesse caso, os membros centrais dos ecléticos apresentariam maior frequência de marcas de pluralidade que os membros periféricos, justamente por serem um pouco mais apegados às normas, inclusive as linguísticas, ditadas pelo contexto escolar. Já os membros centrais dos funkeiros apresentariam uma frequência mais baixa de marcas de pluralidade do que os membros periféricos.

Em linhas gerais, os resultados quantitativos para as CPs de ecléticos e funkeiros corroboram os apontamentos da pesquisa etnográfica, considerando que, em termos gerais, a aplicação da regra normativa de CN é de $92,3 \%$ dos casos possíveis $(228 / 247)$ para os membros dos ecléticos e de 38,1\% (146/236) para os membros dos funkeiros. Pode-se deduzir dessa diferença que o comportamento verbal representa uma das práticas 
sociais, como recurso estilístico de construção de identidade, separando jovens com a mesma idade e escolaridade entre os que aplicam ou não aplicam a regra padrão de concordância.

Confirma essa tendência uma comparação entre dados da comunidade rio-pretense como um todo, com base na amostra Iboruna (GONÇALVES, 2008), e os dados das duas CPs, quantificados segundo os mesmos critérios de faixa etária (SALOMÃOCONCHALO, 2015). Os resultados gerais mostram que os ecléticos apresentam uma frequência de aplicação $(92,3 \%=228 / 247)$ maior que a do grupo controle ${ }^{3}(86,5 \%=$ $192 / 222)$ e os funkeiros, uma frequência significativamente menor $(62 \%=146 / 236)$.

Em outros termos: a constituição das CPs e o perfil social dos integrantes já indiciavam que os membros dos ecléticos apresentariam uma frequência comparativamente mais elevada de marcas de pluralidade do que a dos membros dos funkeiros, o que a análise quantitativa de fato corrobora; comparados com os membros da comunidade da mesma faixa etária, os ecléticos os superam no apego à variedade de prestígio, mas os funkeiros se abrigam numa posição abaixo da média.

O perfil social dos ecléticos inclui preferência por marcar presença nas aulas independentemente dos problemas do quotidiano escolar e busca por formação profissional em cursos técnicos. São essas tendências detectadas na análise etnográfica que apontaram para a projeção de uma expectativa de alta taxa de marcação de pluralidade no SN.

Entre os funkeiros, o reduzido grau de apego às regras normativas acaba se revelando como traço definidor, juntamente com outras características pessoais e práticas sociais. Esse baixo grau de apego à variedade de prestígio é um dos indícios de não identificação com valores do contexto escolar e, possivelmente, um caso de prestígio encoberto.

Vejamos, a seguir, se esses índices gerais se mantêm no comportamento individual dos ecléticos, conforme mostra a Figura 1.

A incidência de marcação de pluralidade no SN é muito elevada, mais de $90 \%$ no desempenho verbal dos informantes W. e C., enquanto R. e L. estão em torno da marca dos $80 \%$, mas é L. quem aplica menos frequentemente a regra de $\mathrm{CN}$ dentro do grupo, como mostra a Figura 2. Essa frequência mais baixa não chega a surpreender em vista da relação de L. com membros de outras CPs. Além de se relacionar com os outros grupos, L. mantém uma relação amistosa com $\mathrm{M}$. As negociações que trava com esse funkeiro e com membros de outros grupos possivelmente tornam L. um membro menos prototípico.

\footnotetext{
${ }^{3} \mathrm{O}$ chamado "grupo controle" representa um recorte do banco de dados Iboruna, correspondente, em termos de variáveis sociais, ao mesmo recorte das CPs, ou seja, faixa etária de 16 a 25 anos, integrantes do Ensino Médio e gêneros masculino e feminino. Foram utilizados oito inquéritos da Amostra Censo que se enquadram nesse perfil (ACs 041, 042, 043, 044, 045, 046, 047 e 048).
} 

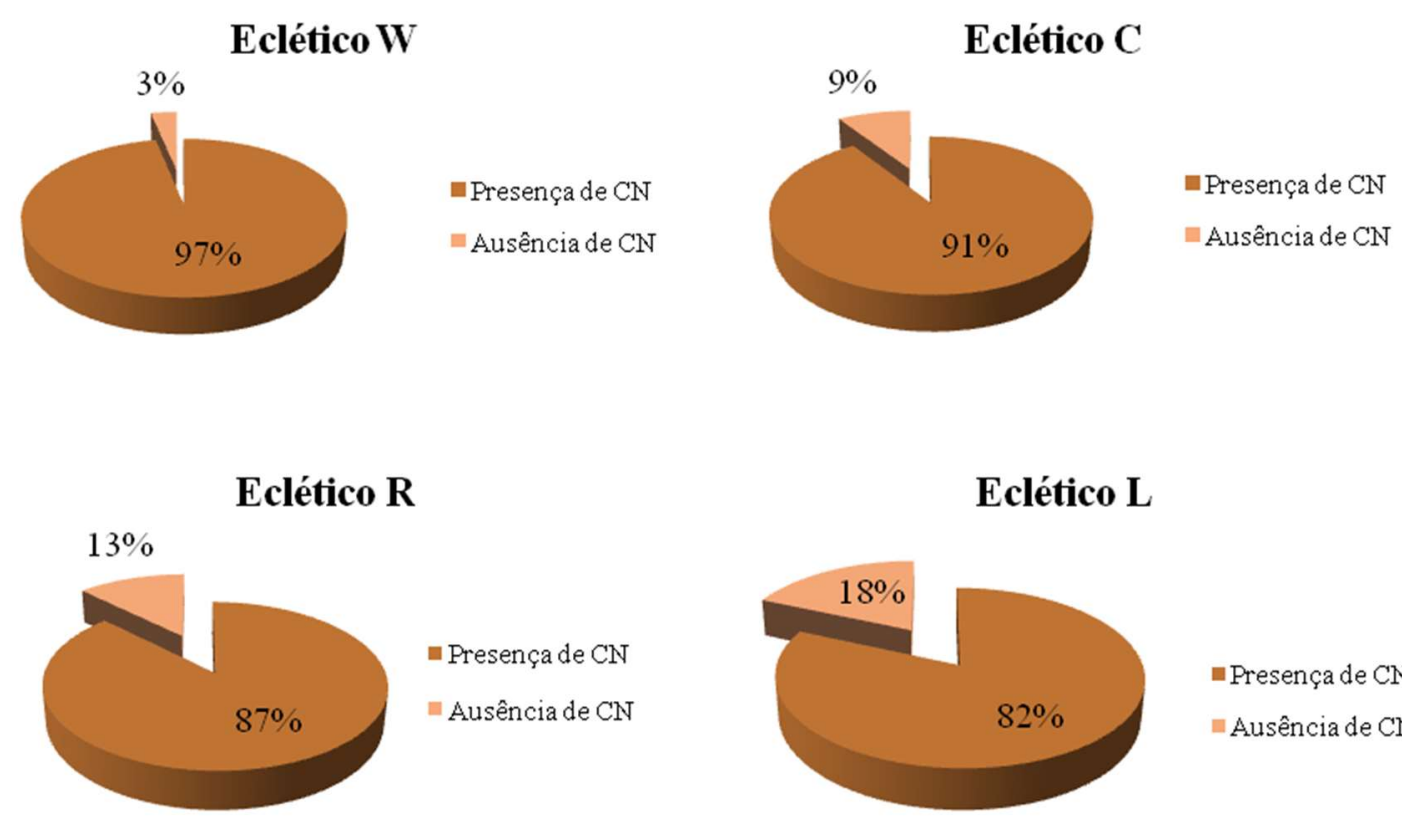

\section{Eclético L}

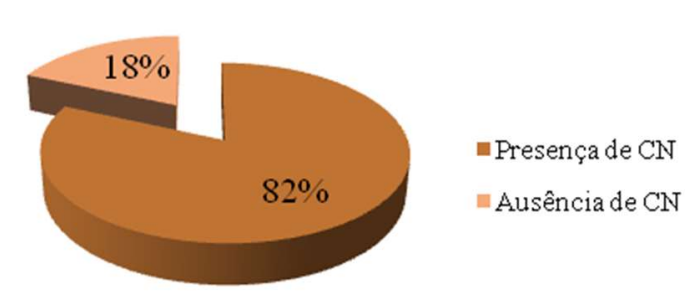

Figura 1. Frequências de marcação de plural dos ecléticos Fonte: Adaptado de Salomão-Conchalo (2015, p. 248)

Vejamos, agora, na Figura 2, a análise individual do comportamento verbal dos funkeiros em relação ao fenômeno investigado.

\section{Funkeiro R}

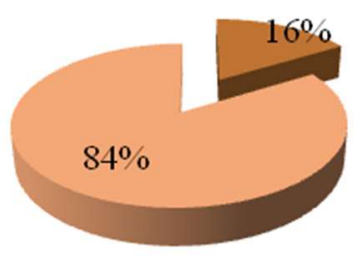

Funkeiro M

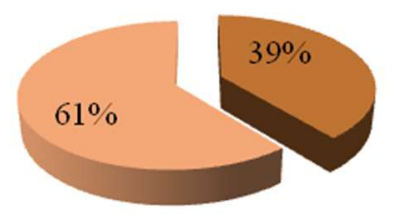

- Presença de CN

- Ausência de CN
Funkeiro P

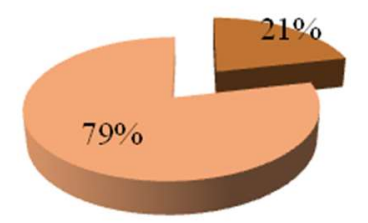

- Presença de $\mathrm{CN}$

- Ausência de $\mathrm{CN}$

Figura 2. Frequências de marcação de plural dos funkeiros Fonte: Adaptado de Salomão-Conchalo (2015, p. 260) 
Os índices de marcação de plural no $\mathrm{SN}$ dos afiliados à $\mathrm{CP}$ dos funkeiros apontam para o "aproveitamento" da regra variável de CN na construção de identidade, um recurso estilístico associado ao modo de se vestir, à música funk e à natureza do comportamento quotidiano. De um modo geral, o comportamento linguístico dos funkeiros é evidência de uma relação inversamente proporcional entre o envolvimento nas práticas sociais da $\mathrm{CP}$ e o apego às marcas de pluralidade.

Os resultados de R. e P., membros centrais dessa CP, mostram baixo grau de cumprimento da regra padrão de concordância. $\mathrm{O}$ funkeiro $\mathrm{M}$. se encontra em uma zona mais neutra de preservação, com um índice positivo beirando o dobro de frequência da média dos membros centrais, embora ainda extremamente baixo se comparado ao da média dos ecléticos. Essa incidência mostra o perfil de membro periférico, mas com forte identificação ideológica com o grupo. É o jovem A., no entanto, que mantém um índice significativo de marcas de pluralidade, o que indicia a emergência da individualidade.

Embora o percurso de acesso à CP possa contribuir para a formação da identidade, uma trajetória periférica nunca conduz o indivíduo à plena participação. Caso exemplar é o de M., jovem que mantém práticas sociais típicas de identificação de um funkeiro, como o comportamento jocoso na aula, o gosto por dança e música funk, participação ativa na divulgação de festas organizadas pelo grupo. Mesmo assim, sua afiliação tem raízes no protagonismo de R., com quem mantém relações ostensivas de amizade.

Esses resultados mostram que a construção de identidade não se encerra com a plena afiliação a uma dada comunidade, já que o desenvolvimento das práticas sociais significativas é um processo contínuo, presente em várias práticas sociais de que resulta a renegociação da própria identidade, cuja consequência mais imediata é a assunção de uma trajetória de saída: quanto maior a frequência de novas negociações e exigências, tanto maior a frequência de desenvolvimento de novas relações. Da necessidade de firmar posições distintas da comunidade resulta também a necessidade de ver o mundo com outro olhar.

Intrigam, no entanto, os índices de aplicação positiva de concordância no comportamento verbal do funkeiro A. Durante a entrevista gravada, a única que foi possível agendar, esse jovem manifestou um comportamento singular. Apesar de tentar chocar a documentadora com a narração de episódios de sua vida sexual, o que é esperado de um funkeiro, mostrou-se obsequioso no uso de formas de tratamento. Em conversas informais, A. referenciava a documentadora por primeiro nome e você, mas não na entrevista, como mostra o exemplo (1).

(1) INF.: aí sim a senhora chegou no ponto ... pra mim ESCOLA ensino médio ... ensino fundamental não influencia nada na faculDADE que eu quero que eu quero exercê(r) ... (EI-Fk/ A./Mc/ L. 24-27)

Fora das circunstâncias de gravação, não demonstrava preocupação alguma com a aplicação da regra padrão de concordância. Uma análise de oitiva das diversas situações de interação permite inferir que A. manifesta uma frequência de ausência de plural similar à de R., um de seus amigos mais próximos, como mostra o exemplo (2), extraído de sua entrevista gravada.

(2) nos primeros dias ... viu que não tava paSSANdo nem um TERço do que tinha que subi(r) pra cheGA(r) onde os traficante tava ... o arsenal intero ... viu as droga que foram presa (EI-Fk/ A./Mc/ L. 445-453) 
Conhecer a história de vida de A. e suas expectativas de continuidade no sistema escolar permite levantar algumas hipóteses explicativas sobre esse estilo cuidadoso. Esse jovem projeta um sentimento de mobilidade social ascendente, que possa vir a contornar os problemas de seu próprio contexto social. Almeja entrar na carreira jurídica, o que implica emblematicamente uma história de vida diferente da vivenciada pelo pai no tráfico e satisfaz, ao mesmo tempo, as expectativas projetadas por sua mãe de que possa vir a desvencilhar-se das antigas amizades do pai, que ainda o cercam como um assédio constante de participação no tráfico.

De um ponto de vista linguístico, seu comportamento indicia simbolicamente a capacidade de usar as normas e de aplicá-las a uma situação formal de interação, quando assim o desejar, a despeito mesmo de não "levar a sério" o Ensino Médio.

Segundo Eckert (2008), atos de identidade não envolvem primariamente a questão de reivindicar pertencimento a este ou a aquele grupo ou categoria, em oposição a outro grupo ou categoria. Além disso, atos de identidade não são independentes da ordem social mais abrangente; pelo contrário, eles são sistematicamente relacionados a categorias macrossociológicas e encaixados nas práticas que as produzem e as reproduzem.

São os elos entre o indivíduo, aqui no caso, o funkeiro A., e a categoria macrossociológica em que ele se enquadra (estar em tal faixa etária, em tal grau de escolaridade) que fornecem as pistas das práticas sociais em que ele atualiza seus modos de falar, movimentando seus estilos conforme movimenta suas máscaras sociais nas situações do quotidiano funkeiro e na situação de entrevista em que exibe habilidades verbais.

Nos dados aqui examinados, a variação de número, um indexador dos valores ideológicos e das práticas sociais que organizam a identidade, passa por um processo de ressignificação tanto para funkeiros quanto para ecléticos, constituindo, assim, o espaço privilegiado do processo de bricolagem (ECKERT, 2008; DAYRELL, 2005), em que a variação estilística se agrega a um repertório pré-existente de outras variáveis, reordenadas segundo os valores de cada grupo para comunicar novos significados.

\section{A construção da identidade e ensino da variedade padrão}

Parece claro que, para os funkeiros, a variação de número não veicula necessariamente valores alternativos de estigma e prestígio; pelo contrário, há momentos de usar a forma de prestígio e momentos de usar a forma estigmatizada. Pode-se afirmar que as práticas sociais os tornam ora adeptos do prestígio manifesto e explícito das marcas formais de plural, ora adeptos de um tipo de prestígio encoberto que os leva ao uso de marcas não formalmente explícitas de plural. A variação de pluralidade é, portanto, apenas um recurso estilístico de construção de identidade, ao assinalar separação e distanciamento entre os grupos e mesmo um perfil individual e próprio, que se destaca dos demais membros do mesmo grupo, como a relação entre A. e sua comunidade de prática.

Marcar ou não marcar pluralidade é uma questão que vai além do compartilhamento do valor social de prestígio atribuído por categorias sociais pré-determinadas, o que permite questionar a própria definição prototípica de prestígio e estigmatização. 
Quando uma variante estigmatizada pela comunidade social como um todo é adotada pelos membros de uma comunidade de prática, desvanece-se o valor de estigma social, justamente por indexar uma marca de afiliação ao grupo, de pertencimento social, e, portanto, de representação simbólica de construção de identidade. Está claro, no entanto, que funkeiros (e também ecléticos) não estão dizendo 'sou um funkeiro' quando empregam uma variante compartilhada por funkeiros, nem estão dizendo "não sou um funkeiro" quando não a empregam. O funkeiro A. não é menos funkeiro por aplicar a regra normativa de concordância nominal com uma frequência mais elevada que seus pares na situação de entrevista. Como esses significados são fluidos, nada a eles relacionado é suscetível de receber uma conclusão definitiva, taxativa.

O mesmo é verdadeiro, guardadas as devidas proporções, para o comportamento dos membros dos ecléticos: aplicar positivamente a regra de $\mathrm{CN}$ significa emblematicamente aproximar-se do que é aceitável pela norma padrão, além de assegurar o distanciamento seguro dos funkeiros em relação às diferenças ideológicas.

Num cenário escolar desse tipo, que procedimentos adotar para o ensino da variedade padrão? Na página 33 dos PCNs, lê-se:

[...] o ensino de Língua Portuguesa deverá organizar-se de modo que os alunos sejam capazes de [...] utilizar diferentes registros, inclusive os mais formais da variedade lingüística valorizada socialmente, sabendo adequá-los às circunstâncias da situação comunicativa de que participam; conhecer e respeitar as diferentes variedades lingüísticas do português falado; $[\ldots]$.

O estabelecimento desse tipo de objetivo, como se sabe, está diretamente relacionado a problemas de aprendizagem resultantes de uma tradição de ensino da norma padrão, língua ideal baseada nas produções escritas e literárias e, portanto, não falada por nenhum segmento social em particular, embora seja mais familiar aos estratos sociais mais favorecidos da população. A proposta de uso de diferentes registros corrige, portanto, a ideia, aceita de longa data, de que a língua em todos os seus usos se circunscreve à norma padrão, além de postular, em seu lugar, o conceito de variedade de prestígio.

É em função desses objetivos que, segundo Barzotto (2004), a relação entre as variedades linguísticas e o trabalho escolar, nos últimos vinte anos, trouxe para o debate a presença constante de pelo menos três verbos: respeitar, valorizar e adequar, usados com pelo menos dois argumentos internos: respeitar e valorizar as variedades do aluno e adequá-las ao ambiente e à situação de uso. Esses três verbos projetam três vertentes no ensino, exaustivamente discutidas por Barzotto (2004), e todas as três "pressupõem que alguém se posicione em um lugar de melhor prestígio, tanto em relação às variedades, como em relação aos seus praticantes. Assim, elas não conseguem propor um deslocamento efetivo das posições discriminatórias" (BARZOTTO, 2004, p. 95). E eu acrescentaria, nem um deslocamento em direção de suas identidades constituídas na prática social, como as discutidas aqui.

A prática pedagógica que esse autor postula tem mais a ver com o verbo incorporar por sugerir um espaço de trabalho com as variedades de fato praticadas pelo aluno. Nesse espaço, seria possível explorar não apenas a produtividade das variedades no uso quotidiano e na construção de identidade, mas também na produção artística, passível de emergir em letras de músicas, dramaturgias e manifestações literárias (BARZOTTO, 2004, p. 95). 
Numa proposta como essa, a língua portuguesa é entendida como um conjunto de variedades, mas sem se identificar com uma delas, a que goza de maior prestígio, como ocorre na tradição normativa.

É por isso que ela é capaz de incorporar inclusive o caráter fluido do prestígio e da estigmatização, que configura o modo de resistência dos jovens que navegam por comunidades de prática em oposição a instituições constituídas por relações socialmente rígidas como a escolar. Incorporar essas práticas sociais parece ser um aspecto crucial para o sucesso do ensino. Admitir ou receber as variedades na sala de aula, sem a hierarquização e a valoração, implicadas no uso dos verbos respeitar, valorizar e adequar significa não apenas contemplar os parâmetros curriculares, mas também os ditames do Título I, Art. 3", Parágrafo IV da Constituição: "promover o bem de todos, sem preconceitos de origem, raça, sexo, cor, idade e quaisquer outras formas de discriminação", citados por Barzotto (2004, p. 94).

\section{REFERÊNCIAS}

BARZOTTO, V. H. Nem respeitar, nem valorizar, nem adequar as variedades linguísticas. Revista Ecos, Cáceres, v. 2, p. 93-96, 2004.

CHAMBERS, J. K. Sociolinguistic theory. Cambridge, Mass.: Blackwell Publishers, 1995.

DAYRELL, J. A música entra em cena: o rap e o funk na socialização da juventude. Belo Horizonte: UFMG, 2005.

ECKERT, P. Linguistic variation as social practice. Oxford: Blackwell, 2000.

. Variation, convention, and social meaning. Paper presented at the Annual Meeting of the Linguistic Society of America. Oakland CA. Jan 7, 2005.

Variation and the indexical field. Journal of Sociolinguistics, v. 12, n. 4, p. 453-476, 2008.

Three waves of variation study: the emergence of meaning in the study of sociolinguistic variation. Annual Review of Anthropology, n. 41, p. 87-100, 2012.

GONÇALVES, S. C. L. Projeto ALIP (Amostra Linguística do Interior Paulista): questões teóricas e metodológicas sobre a constituição de um banco de dados de língua falada. In: TAGNIN, E. O.; VALE, O. A. Avanços da linguística de corpus no Brasil. São Paulo: Humanitas, 2008. p. 217-245.

LABOV, W. Sociolinguistic Patterns. Philadelphia: Pennsylvania University Press, 1972.

. Estágios na aquisição do inglês standard. Tradução de Luiza Leite Bruno Lobo. In: FONSECA, M.; STELLA, V.; NEVES, M. F. (Org.). Sociolinguística. Rio de Janeiro: Eldorado, 1974 [1964]. p. 49-85.

MILROY, L. Language and social networks. Oxford: Blackwell, 1987 [1980].

SALOMÃO-CONCHALO, M. H. A variação estilística na concordância nominal e verbal como construção de identidade social. 2015. $314 \mathrm{f}$. Tese (Doutorado em Estudos Linguísticos) - Instituto de Biociências, Letras e Ciências Exatas, Universidade Estadual Paulista, São José do Rio Preto, 2015. 
TRUDGILL, P. Sex, covert prestige and linguistic change in the urban British English of Norwich. Language in society, v. 1, p. 179-196, 1972.

Recebido em: 26/09/2016

Aprovado em: 29/11/2016 